\title{
The Evolution of the Dynamic Modulus of Fly Ash Soil under the Freeze-thaw Cycles
}

\author{
Chen Jia-feng ${ }^{1}$ \\ College of traffic, Jilin University \\ Changchun, China \\ 1043937698@qq.com \\ Wei Hai-bin ${ }^{2}$ \\ College of traffic, Jilin University \\ Changchun, China \\ weihb@jlu.edu.cn
}

\author{
$\mathrm{Li} \mathrm{Li}$ \\ College of traffic, Jilin University \\ Changchun, China \\ 874909268@qq.com \\ Chang Ming-ming \\ College of traffic, Jilin University \\ Changchun, China \\ 824561210@qq.com
}

\begin{abstract}
This paper derived a damage function model of fly ash soil that under the effect of freeze-thaw cycles by using the penetration test and the basic theory of damage mechanics. The Calculated data of the model have a high degree of agreement with the measured data. This model provides a new way for the study of fly ash soil subgrade dynamic modulus in the seasonal frozen area.
\end{abstract}

Index Terms-Permeability coefficient, dynamic modulus, freeze-thaw cycles, fly ash soil.

\section{INTRODUCTION}

The domestic and foreign researches show that the fly ash soil has good performance in improving the frost resistance of the subgrade. By making use of fly ash, we turn the waste into treasure, reducing the fly ash pollution effectively. Many scholars have done a lot of experimental and theoretical research on the permeability coefficient and dynamic modulus in the seasonal frost area. But there are few researches considering the freeze-thaw and penetration action at the same time. Also, it is troublesome to test the dynamic characteristics of the subgrade directly. Therefore, this paper attempts to make a systematic study of the fly ash soil permeability coefficient under the conditions of freeze-thaw cycles by stimulating the conditions in laboratory. At last, the author build a fly ash soil dynamic modulus injury model by taking advantage of the rule that our research group had made in the National High Technology Research and Development Program ("Research on the Embankment Anti-freeze-thaw Stability Control Technology in Seasonal Frost Region"). This model can calculate the dynamic modulus by testing the permeability coefficient and freeze-thaw cycles. It can bring some convenience for the roads design and disease prevention in seasonal frozen area.

\section{PROCEDURES OF THE FREEZE-THAW CYCLES AND PERMEATION TEST}

On the basis of the previous researches that our research group had done, the author determined the fly ash and the soil best ratio was 1:2 and made specimens. In this test, the natural moisture content of the soil samples were measured by the drying method. The density was measured by the cutting ring method. The liquid limit and the plastic limit were measured by the joint analyzer of the liquid limit and the plastic limit. The basic physical indicators of the test soil samples are shown in Table.1.

Table.1 Basic physical indicators of the test soil samples

\begin{tabular}{cccccc}
\hline $\begin{array}{c}\text { Natural } \\
\text { moisture } \\
\text { content }\end{array}$ & $\begin{array}{c}\text { Density } \\
\left(\mathrm{g} / \mathrm{cm}^{3}\right)\end{array}$ & $\begin{array}{c}\text { Liquid } \\
\text { limit } \\
(\%)\end{array}$ & $\begin{array}{c}\text { Plastic } \\
\text { limit } \\
(\%)\end{array}$ & $\begin{array}{c}\text { Plasticity } \\
\text { index }\end{array}$ & $\begin{array}{c}\text { Liquid } \\
\text { limit } \\
\text { index }\end{array}$ \\
\hline 20.6 & 1.52 & 41.71 & 19.78 & 21.93 & 0.004 \\
\hline
\end{tabular}

The specimens were made by the standard compaction method. The specimens should be wrapped with the cling film to prevent the water evaporation. In the experiment, 18 specimens were divided into 9 groups, and in each group there are two specimens. Their heights are all $100 \mathrm{~mm}$, and their diameters are all $70 \mathrm{~mm}$. The forming specimens are shown in Fig.1.

In the seasonal frozen area, the subgrade in a frozen period will go through several freeze-thaw cycles. In this paper, the freeze-thaw test was done indoor. According to the data in seasonal frost region, the freeze-thaw temperature was chosen from $-5^{\circ} \mathrm{C}$ to $5^{\circ} \mathrm{C}$. The specimens were all put into the freezethaw box, except for the two comparison ones. Took the temperature gradient as $1^{\circ} \mathrm{C}$, ranged the temperature from $5^{\circ} \mathrm{C}$ to -5 every 24 hours, then the next 24 hours ranged from $-5^{\circ} \mathrm{C}$ to $5^{\circ} \mathrm{C}$. This is one freeze-thaw cycle. After each freeze-thaw cycle, the author removed two specimens from the box to do the permeation test. The mean value of the permeability coefficient was set as the final value. The summary data of permeation test are shown in Table.2. 


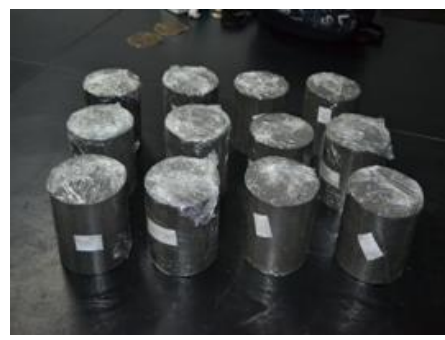

Fig. 1. Specimens.

\section{TEST ANALYSIS}

\section{A. Dynamic modulus of freeze-thaw injury model}

Through the calculation of the permeability coefficient under different freeze-thaw cycles, it can be seen that there is a significant bias for the calculation value of No.16 specimen. So the author removed it from the experimental data. According to Table.2, permeability coefficient curve was draw, as show in Fig.2.

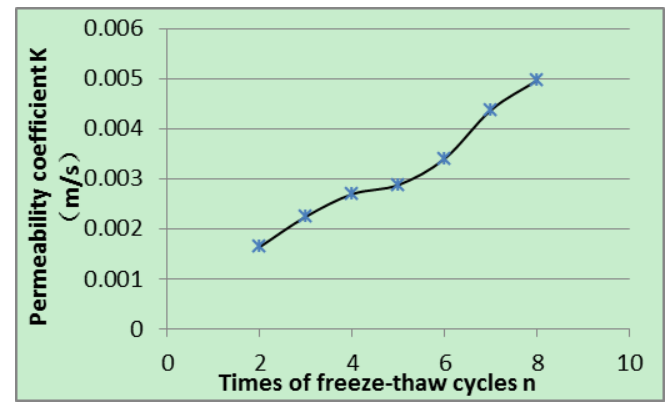

Fig. 2. Permeability coefficient curve.

As we can see from Fig.2, after freeze-thaw cycles the permeability coefficient of specimens has a significant increase. With the increase of the times of freeze-thaw cycles, the permeability coefficient is also increasing. Observing the specimens, there was no obvious cracks on the surface of the specimen that without freeze-thaw cycles. In the meaning while, there were some small cracks on the surface of the specimen that with several freeze-thaw cycles.

For damaged materials, it is difficult to determine the effective bearing area of the material by analyzing the kind of defect forms and the mechanisms of injury from microcosmic. So Lemaitre proposed the strain equivalence principle in 1973. He believes that the deformation behavior of the damaged material can be embodied by effective stress. That is to say the strain caused by the stress $\sigma$ in the damaged material is equivalent to the strain caused by the effective stress in the non-damaged material, as show in Fig.3.
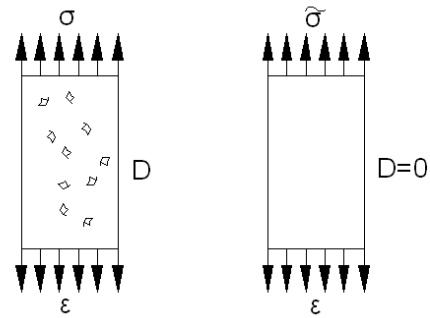

Fig. 3. Strain equivalent schematic diagram.

According to the strain equivalence principle, the constitutive relation of the damaged material can be obtained by the Cauchy stress in the non-destructive material. The onedimensional linear elastic material constitutive relation of the damaged material is as follows:

$$
\varepsilon=\frac{\sigma}{\widetilde{E}}=\frac{\tilde{\sigma}}{E}=\frac{\sigma}{(1-D) E} \cdots \cdots \cdots(1)
$$

In the formula, $\mathrm{E}$ is the elastic modulus. The damage process of materials is the reducing of its modulus of elasticity from $\mathrm{E}$ to $\tilde{E}$. Also $\tilde{E}=(1-D) E$ is known as the effective elastic modulus of the damaged material. So we can also define the degree of damage $\mathrm{D}$ as:

Table. 2 Summary data of permeation test

\begin{tabular}{|c|c|c|c|c|c|c|c|c|}
\hline $\begin{array}{l}\text { Times of } \\
\text { freeze-thaw } \\
\text { cycle }\end{array}$ & No. & $\begin{array}{c}\text { Seepage } \\
\text { path }(\mathrm{cm})\end{array}$ & $\begin{array}{c}\text { Hydrostatic } \\
\text { pressure } \\
\text { h }(\mathrm{cm})\end{array}$ & $\begin{array}{l}\text { Time } \\
(\min )\end{array}$ & $\begin{array}{c}\text { Dropped water } \\
\text { head } \\
\mathrm{H}(\mathrm{mm})\end{array}$ & $\begin{array}{c}\text { Water pressure } \\
\text { Gradient }\end{array}$ & $\begin{array}{l}\text { Permeability } \\
\text { coefficient } \\
\mathrm{K}(\mathrm{m} / \mathrm{s})\end{array}$ & $\begin{array}{l}\text { Mean } \\
\text { value } \\
\mathrm{K}(\mathrm{m} / \mathrm{s})\end{array}$ \\
\hline \multirow{2}{*}{0} & 1 & 0.7 & 4 & 41 & 2.0 & 5.714 & 0.000854 & \multirow{2}{*}{0.000816} \\
\hline & 2 & 0.7 & 4 & 45 & 2.0 & 5.714 & 0.000778 & \\
\hline \multirow{2}{*}{1} & 3 & 0.7 & 4 & 30 & 2.0 & 5.714 & 0.001167 & \multirow{2}{*}{0.001313} \\
\hline & 4 & 0.7 & 4 & 60 & 5.0 & 5.714 & 0.001458 & \\
\hline \multirow{2}{*}{2} & 5 & 0.7 & 4 & 59 & 6.0 & 5.714 & 0.001780 & \multirow{2}{*}{0.001640} \\
\hline & 6 & 0.7 & 4 & 70 & 6.0 & 5.714 & 0.001500 & \\
\hline \multirow{2}{*}{3} & 7 & 0.7 & 4 & 42 & 5.0 & 5.714 & 0.002083 & \multirow{2}{*}{0.002245} \\
\hline & 8 & 0.7 & 4 & 40 & 5.5 & 5.714 & 0.002406 & \\
\hline \multirow{2}{*}{4} & 9 & 0.7 & 4 & 40 & 6.0 & 5.714 & 0.002625 & \multirow{2}{*}{0.002694} \\
\hline & 10 & 0.7 & 4 & 38 & 6.0 & 5.714 & 0.002763 & \\
\hline \multirow{2}{*}{5} & 11 & 0.7 & 4 & 37 & 6.0 & 5.714 & 0.002838 & \multirow{2}{*}{0.002878} \\
\hline & 12 & 0.7 & 4 & 42 & 7.0 & 5.714 & 0.002917 & \\
\hline \multirow{2}{*}{6} & 13 & 0.7 & 4 & 40 & 8.0 & 5.714 & 0.003500 & \multirow{2}{*}{0.003406} \\
\hline & 14 & 0.7 & 4 & 37 & 7.0 & 5.714 & 0.003311 & \\
\hline \multirow{2}{*}{7} & 15 & 0.7 & 4 & 40 & 10.0 & 5.714 & 0.004375 & \multirow{2}{*}{0.004375} \\
\hline & 16 & 0.7 & 4 & 32 & 10.0 & 5.714 & 0.005469 & \\
\hline \multirow{2}{*}{8} & 17 & 0.7 & 4 & 41 & 12.0 & 5.714 & 0.005122 & \multirow{2}{*}{0.004968} \\
\hline & 18 & 0.7 & 4 & 40 & 11.0 & 5.714 & 0.004813 & \\
\hline
\end{tabular}




$$
D=1-\frac{\tilde{E}}{E}
$$

Referencing to the permeability coefficient of fly ash soil specimen increases with the increasing of the times of freezethaw cycles, we can see that the action of the freeze-thaw makes the micro-cracks in the fly ash soil specimens increasing. So we can define the freeze-thaw injury degree $D^{\prime}$ by permeability coefficient:

$$
D^{\prime}=1-\frac{K}{\widetilde{K}} \cdots \cdots \cdots(3)
$$

Where: $\mathrm{K}-$ Initial permeability coefficient; $\tilde{K}-$ Permeability coefficient of the damaged material.

The initial boundary conditions value of the damage variable are shown in Table.3, we can see two initial boundary conditions values of the damage variable are all the same.

Table. 3 Initial boundary conditions value

\begin{tabular}{ccc}
$\begin{array}{c}\text { Damage } \\
\text { variable }\end{array}$ & $\begin{array}{c}\text { Boundary } \\
\text { conditions } \\
\text { Initial lossless } \\
\text { status }\end{array}$ & $\begin{array}{c}\text { Complete damage } \\
\text { status }\end{array}$ \\
\hline$D^{\prime}$ & $D^{\prime}=0$ & $D=1$ \\
$D^{\prime}=0$ & $D^{\prime}=1$
\end{tabular}

Since the two initial values are identical, we can assume that the decrease of effective elastic modulus and decrease of the effective bearing area in material damage are equivalent. Meanwhile, the decrease of effective bearing area is the manifestation of the increase in material micro-cracks. So we can assume that the decrease of effective elasticity modulus and the increase of permeability coefficient in damage to the material are equivalent. Therefore we can make $D=D^{\prime}$, i.e.:

$$
1-\frac{\tilde{E}}{E}=1-\frac{K}{\widetilde{K}} \cdots \cdots \cdots
$$

Formula (4) can be simplified as:

$$
E=\frac{K}{\widetilde{K}} E \cdots \cdots \cdots(5)
$$

\section{B. Modification of the dynamic modulus of freeze-thaw injury model}

The author corrected the dynamic modulus of freeze-thaw injury model with previous research group dynamic modulus experimental data (As shown in Table.4). The dynamic modulus of fly ash soil becomes stable after three to five freeze-thaw cycles and the frost durability is better then. Therefore, we chose the dynamic modulus that from 2 to 8

\begin{tabular}{|c|c|c|c|c|c|c|c|}
\hline $\mathrm{n}$ & 2 & 3 & 4 & 5 & 6 & 7 & 8 \\
\hline$\tilde{K}$ & 0.0016 & 0.0022 & 0.0027 & 0.0029 & 0.0034 & 0.0044 & 0.004968 \\
\hline$\tilde{E}$ & 210.10 & 190.46 & 180.25 & 175.64 & 171.79 & 164.24 & 164.81 \\
\hline
\end{tabular}
freeze-thaw cycles to modify the model.

Table.4 Summary of dynamic modulus under 300KPa confining pressure and permeability coefficient

The dynamic modulus-permeability coefficient relationship curve is shown in Fig.4.

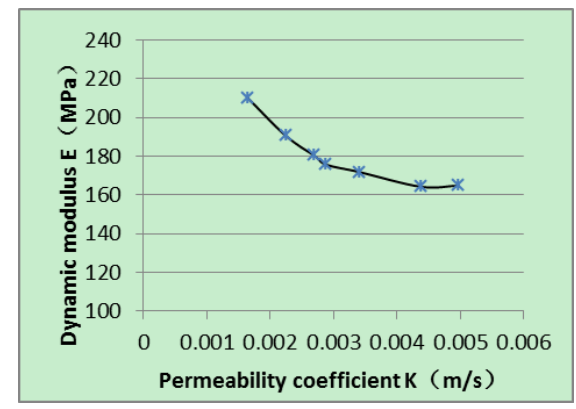

Fig. 4. Relationship curve of dynamic modulus-permeability coefficient

According to the previous relevant research of our research group, the damage math model of the dynamic modulus is:

$$
E_{i}=\frac{n}{a+b n}+\frac{80}{n-1}
$$

Where: Ei stands for dynamic modulus after i times freezethaw cycles; $\mathrm{n}$ stands for freeze-thaw cycles; $\mathrm{a}$ and $\mathrm{b}$ are undetermined coefficients.

Taking into account the times of freeze-thaw cycles $n$ also has an impact on the dynamic modulus, the author modified the equation (5) with equation (6). Then the modified dynamic modulus of freeze-thaw injury model was got:

$$
\tilde{E}=\frac{K}{\widetilde{K}} E+\frac{n}{a+b n}+\frac{c}{n-1} \text {. }
$$

Where: $\mathrm{E}$ is the initial dynamic modulus, $\mathrm{E}=131.04 \mathrm{MPa}$; $\mathrm{K}$ is the initial permeability coefficient, $\mathrm{K}=0.000816 \mathrm{~m} / \mathrm{s}$; $\mathrm{n}$ is the number of freeze-thaw cycles; $a, b, c$ are coefficients to be determined.

The author used software 1stopt for nonlinear fitting, getting $a=0.0014, b=0.0070, c=16.0395$. And the correlation coefficient $\mathrm{R}=0.9956$. The measured and calculated value of dynamic modulus under freeze-thaw cycles are shown in Table.5.

Table.5 Measured and calculated values Of dynamic modulus

\begin{tabular}{cccccccc}
\hline $\begin{array}{c}\text { Times of } \\
\text { freeze- } \\
\text { thaw } \\
\text { cycle }\end{array}$ & 2 & 3 & 4 & 5 & 6 & 7 & 8 \\
\hline $\begin{array}{c}\text { Measured } \\
\text { values } \\
(\mathrm{MPa})\end{array}$ & 210.10 & 190.46 & 180.25 & 175.64 & 171.79 & 164.24 & 164.81 \\
$\begin{array}{c}\text { Calculated } \\
\text { values } \\
\text { (MPa) }\end{array}$ & 210.42 & 188.87 & 180.37 & 177.80 & 172.12 & 165.27 & 162.45 \\
$\begin{array}{c}\text { Relative } \\
\text { errors }(\%)\end{array}$ & 0.15 & -0.84 & 0.067 & 1.23 & 0.19 & 0.63 & -1.43 \\
\hline
\end{tabular}

The curves of measured and calculated values of dynamic modulus are shown in Fig.5. 


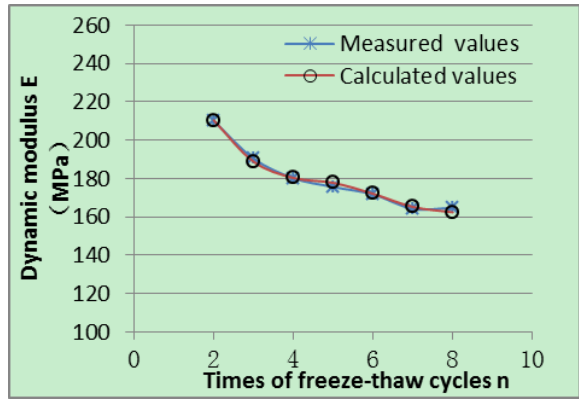

Fig.5. Curves of the Measured and calculated values of dynamic modulus

\section{CONCLUSION}

The calculated and experimental values of the dynamic modulus are in good agreement. It indicates that the dynamic modulus of freeze-thaw injury model we have built has a high accuracy. Testing the dynamic modulus in seasonal frost area is relatively troublesome. Using the freeze-thaw injury model of dynamic modulus we have built can calculate the dynamic modulus by testing the permeability coefficient in seasonal frost area. This model can bring some convenience for the road design and diseases prevention and treatments in seasonally frozen region.

\section{REFERENCES}

[1] Simonesn E Isaesson U. Soil behavior during freezing and thawing using variable and confining pressure triaxial tests [J].Canadian Geotechnical Journal.2001, pp.863-875.

[2] Kennard J M, Morgenstern N R. The segregation potential of a freezing soil $[\mathrm{J}]$.Canadian geotechnical engineering journal. 1981, pp.482-492.

[3] WEI Hai-bin. Dynamic properties of damage for fly ash soil after freeze-thaw cycles. Journal of Harbin Institute of Technology. 2009, pp.0-113.

[4] Yaykiran M. The effect of weathering cycles on fly ash stabilized soft soil. MS thesis, The University of Texas at San Antonio. 2008.

[5] A. Kumar, B. Singh, B. Asheet. Influence of fly ash, lime, and polyester fibers on compaction and strength properties of expansive soil. Journal of Materials in Civil Engineering. 2007, pp. 242-248. 